ORIGINAL PROF-2151

\title{
GROWTH HORMONE ESTIMATION;
}

Insulin-like growth factor-1 a possible alternative

Dr. M. Nadeem Hameed, Dr. Fauzia Sadiq, Dr. Asim Mumtaz, Dr. Hina Mohiuddin, Dr. Sana Khan, Dr. Tariq Jaffar Quereshi

ABSTRACT...Introduction: Despite the use of growth hormone replacement therapy for decades, our ability to make a definitive diagnosis of growth hormone deficiency in children is limited. Growth hormone stimulation tests have been used to discriminate between Growth hormone deficiency and idiopathic short stature. However all these tests lack reproducibility, accuracy, cost affectivity and safety. Insulinlike growth factor-1 is an effector hormone and its serum level may be used as simple, easy to perform diagnostic test for growth hormone deficiency. Objective: To determine the efficacy of IGF-1 as a diagnostic tool in children with growth hormone deficiency. Study Design: Prospective cross sectional survey. Place of Study: Departments of Pediatrics and Pathology, Shalamar Medical \& Dental College, Lahore. Duration of study: 1 st July to 31st December, 2011. Material \& Methods: We included 40 children of $3.5-17$ year age and detailed clinical data was collected. All these children were subjected to stimulation by standardized exercise on treadmill, after taking basal blood samples for GH and IGF-1. Post stimulation growth hormone was recorded to identify growth hormone deficient children. Results: 17 (42.5\%) children had post stimulation growth hormone level $<10 \mathrm{ng} / \mathrm{ml}$ while $23(57.5 \%)$ had values $>10 \mathrm{ng} / \mathrm{ml}$. Post exercise stimulation GH level showed weak correlation with IGF-1 in either of the two study groups. P value was found $>0.05$ in deficient as well as sufficient groups, depicting non significance of IGF-1 in relation to post stimulation GH level. Conclusions: IGF-1 is not a suitable surrogate diagnostic marker for growth hormone deficiency. Diagnosis should always be based on combination of auxological biochemical, radiological and genetic considerations, Abbreviations: GHD - Growth Hormone Deficiency, GH - Growth Hormone, GHSTs - Growth Hormone Stimulation Tests, IGF-1 - Insulin-like Growth Factor-1, MPH - Mid Parental Height, BA - Bone Age.

Key words: Growth Hormone Deficiency, Insulin-like growth factor, IGF-1, Short Stature

Article Citation

Hameed MN, Sadiq F, Mumtaz A, Mohiuddin H, Khan S, Quereshi TJ. Growth Hormone Estimation; Insulin-like growth factor-1 a possible alternative. Professional Med J 2013;20(3): 385-389.

\section{INTRODUCTION}

Growth hormone deficiency (GHD) although considered uncommon, is one of the treatable causes of short stature'. Definitive diagnosis of GHD remains a diagnostic challenge despite passage of about half a century since Growth hormone $(\mathrm{GH})$ is being used as a replacement therapy². Various growth hormone stimulation tests (GHSTs) have been used to discriminate between GHD and idiopathic short stature. This stimulation of $\mathrm{GH}$ can be induced by various physiological stimuli like fasting, sleep or exercise as well as pharmacological stimuli like Ldopa, clonidine, glucagon, propranolol, arginine or insulin infusion ${ }^{2,3,4}$. However all these tests lack reproducibility, accuracy, cost affectivity and safety ${ }^{4}$. Apart from a number of clear genetic causes of GHD, the diagnostic gold standard remains elusive. Nevertheless correct diagnosis has significant benefits to the child guiding both future investigations and management ${ }^{5}$.

Insulin-like growth factor-1 (IGF-1) is an effecter hormone which is essential for normal growth in humans and has an important role in mediating the effect of growth hormone ${ }^{6}$. Several studies have shown that serum levels of IGF-1 are growth hormone dependent ${ }^{7}$. Measurements of serum IGF-1 concentration seem to be a simple, reliable, relatively easy to perform test, as a substitute to GHSTs in diagnosis of GHD ${ }^{8,9}$. IGF-1 has also been used as a monitoring tool for children receiving growth hormone therapy ${ }^{10}$.

Various locally conducted studies ${ }^{11,12}$ have focused on GHSTs but very few studies ${ }^{13}$ have evaluated the role of IGF-1 in diagnosis of GHD in short stature children. Therefore a clinical trial was planned at Shalamar Medical \& Dental College for this purpose. 


\section{Objective}

To determine the efficacy of IGF-1 as a diagnostic tool in children with growth hormone deficiency.

\section{PATIENTS AND METHODS}

Place of Study: Departments of Pediatrics and Pathology, Shalamar Medical \& Dental College, Lahore Study Design: Prospective cross sectional survey.

\section{Duration of study}

$1^{\text {st }}$ July to $31^{\text {st }}$ December, 2011

\section{Sample type}

Non probability consecutive sampling.

\section{Inclusion Criteria}

Children presenting to outpatient department of Pediatrics at Shalamar Medical \& Dental College with concern of short stature (height less than $5^{\text {TH }}$ centile for age and sex), during the period of study were included.

\section{Sampling}

Consecutive sampling was performed.

\section{Exclusion Criteria}

Children having one of the following:

I. Age less than 3 years

II. Patients with any chronic illness

III. Patients on long term steroid therapy

IV. Children with other known endocrinopathies

V. Children with known genetic syndromes or skeletal disorders

VI. Children not able to perform 20 minutes standardized exercise either due to their weakness or non-cooperation.

VII. Parents did not give consent to participate in the study.

\section{METHODS}

All included patients were assessed in our outpatient Pediatric Unit for short stature. Detailed history including family history, dietary habits and history regarding chronic illness or use of steroids was taken. Exact Height and weight were plotted on centile charts for chronological age (CA). Pubertal stage was assessed by Tanner's score. The onset of puberty was defined clinically by the appearance of breast development in girls and a testicular length of $30 \mathrm{~mm}$ or more in boys. For each child, the family history and parental heights and mid parental height (MPH) were recorded, with calculation of the target height as absolute value. Bone age (BA) was assessed using the Gruelich \& Pyle method ${ }^{14}$.

All include patients were subjected to $\mathrm{GH}$ provocative test with exercise stimulation. Each patient was made to run on the treadmill for 20 minutes continuously with standardized increase in the speed after every five minutes. This procedure was adopted for all the patients undergoing exercise stimulation tests. The procedure was supervised by a pediatrician. Blood samples were taken at baseline for GH, IGF-I and BSR levels, and then after the exercise samples were again taken for GH levels.

Written informed consent was taken by parent/legal guardian before any study-related activities and the children were informed completely about the $\mathrm{GH}$ provocative test (exercise stimulation test) and its protocol.

GH was measured using ELISA method using kit manufactured by Raybio Human GH ELISA (Cat. \# ELH-GH-001). IGF-1 was also measured by ELISA method using kit manufactured by Demeditec Cat. \# DE4140 IGF-1 600 ELISA). Both the assays were standardized as per protocol controls were run in duplicate.

\section{STATISTICAL ANALYSIS}

SPSS 17.00 was used to analyze the data. Pearson Correlation was applied to determine any relationship between variables. Mean \pm SD was also used for descriptive analysis for quantitative variables. 
Student's t-test was applied for determining the statistical difference. A $p<0.05$ was taken for statistical significance.

\section{RESULTS}

Out of 40 children with short stature included in the study, 23 (57.5\%) were male and 17 (42.5\%) were female. Mean age of included cases was 13.01 year (range 3.5 - 17 year).Depending upon the level of growth hormone following stimulation by 20 minutes controlled exercise; children were divided into two groups (figure 1). Mean post-stimulation $\mathrm{GH}$ was $4.31+2.20 \mathrm{ng} / \mathrm{ml}$ in deficient group compared with $31.95+-18.34 \mathrm{ng} / \mathrm{ml}$ in sufficient group (table 1 , figure 2). Post exercise stimulation GH level showed weak correlation with IGF-1 in either of the two study groups (table 2). P value was found $>0.05$ in deficient as well as sufficient groups, depicting non significance of IGF-1 in relation to post stimulation GH level.

\begin{tabular}{|c|c|c|c|c|c|c|}
\hline \multirow[t]{2}{*}{ Variables } & \multicolumn{3}{|c|}{ Post-stimulation $\mathrm{GH} \leq 10 \mathrm{ng} / \mathrm{ml}(\mathrm{n}=17)$} & \multicolumn{3}{|c|}{ Post-stimulation $\mathrm{GH}>10 \mathrm{ng} / \mathrm{ml}(\mathrm{n}=23)$} \\
\hline & Mean \pm SD & Minimum & Maximum & Mean \pm SD & Minimum & Maximum \\
\hline Age & $13.40 \pm 2.011$ & 8.00 & 17 & $12.72+2.66$ & 3.50 & 17 \\
\hline Post Stimulation GH & $4.31 \pm 2.20$ & 0.08 & 9.00 & $31.95+\_18.34$ & 10.18 & 73.29 \\
\hline Serum IGF-1 & $38.77 \pm 21.22$ & 8.11 & 68.54 & $43.96+\_27.67$ & 6.60 & 110.40 \\
\hline
\end{tabular}

Table-I. Comparison of outcome variables between two study groups

\begin{tabular}{|c|c|c|c|}
\hline Value & $\begin{array}{c}\text { Overall } \\
\text { Post-stimulation } \\
\text { GH }\end{array}$ & $\begin{array}{c}\text { Post-stimulation } \\
\mathbf{G H} \leq \mathbf{1 0} \mathbf{n g} / \mathbf{m l} \\
\mathbf{n}=\mathbf{1 7}\end{array}$ & $\begin{array}{c}\text { Post-stimulation } \\
\mathbf{G H}>\mathbf{1 0} \mathbf{n g} / \mathbf{m l} \\
\mathbf{n = 2 3}\end{array}$ \\
\hline$r$ & 0.274 & 0.216 & 0.329 \\
\hline$p$ & 0.087 & 0.406 & 0.126 \\
\hline
\end{tabular}

Table-II. Correlation of post stimulation GH with serum IGF-1

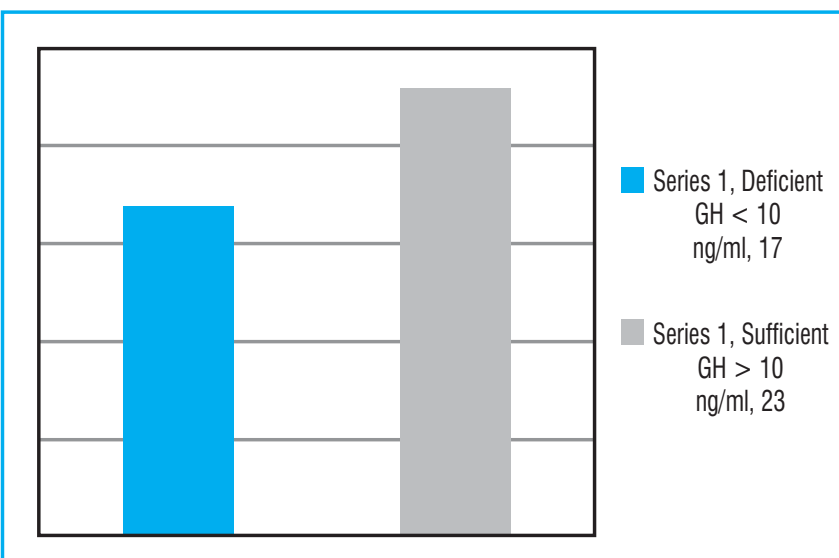

Figure-1. Frequency of deficient and sufficient group

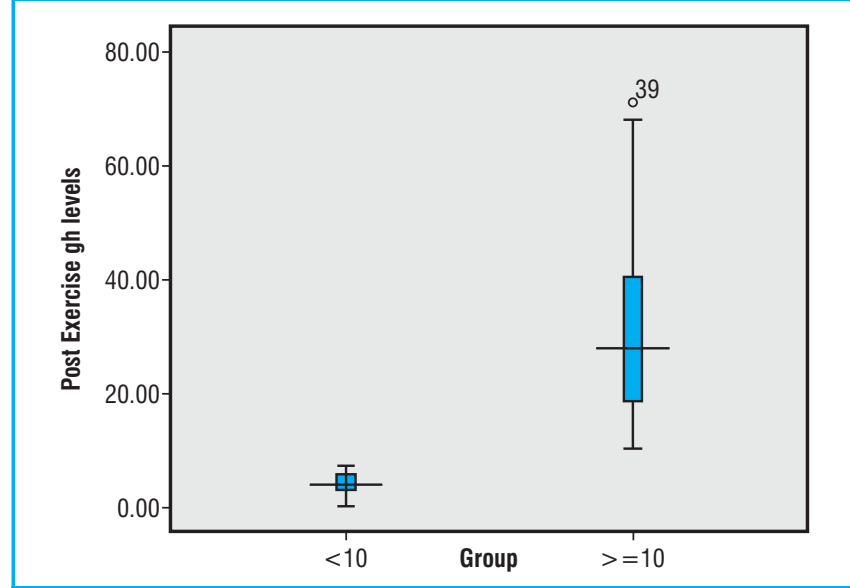

Figure-2. Post exercise GH level, less than $10 \mathrm{nl} / \mathrm{ml}$ vs $>=10 \mathrm{ng} / \mathrm{ml}$

\section{DISCUSSION}

The interpretation of serum IGF-1 has several serious limitations, one of which is that values are age dependent. Levels slowly increase with advancing age till reaching peak at puberty and fall thereafter ${ }^{10}$. Moreover, low IGF-1 levels are reported with malnutrition and chronic illnesses, which need to be 
excluded with certainty before measuring IGF-1 concentration. Since associated chronic malnutrition is so prevalent in our country, this test can be of limited value in most of our patients.

In our study, exercise stimulation was used as screening test for growth hormone deficiency due to safety and convenience, as studies which compared various GHST have depicted that exercise stimulation has high sensitivity and accuracy to diagnose growth hormone deficiency ${ }^{13}$. Standardized exercise on treadmill was used for stimulation to avoid error. Children not able to perform this exercise protocol were already excluded. $42.5 \%$ children with short stature were found to have deficient GH which is a bit higher than figures from locally performed studies ${ }^{11}$. The correlation between post stimulation growth hormone and IGF-1 detected in similar studies in this region, ${ }^{8,13}$, could not be established in our study. Moreover studies which have suggested IGF-1 as a reliable screening test for GHD, have not done this with limitations ${ }^{8}$.

Secretion of IGF-1 is GH dependent; however the data on using IGF-1 as a screening diagnostic tool is not consistent. Our study strongly supports the fact that IGF-1 cannot serve as a surrogate diagnostic tool when used in isolation. This conclusion is consistent with many internationally published studies in recent years ${ }^{6,15,16}$ which fail to find strong correlation between $\mathrm{GH}$ and IGF-1. Diagnosis of GHD should always be based on combination of auxological biochemical, radiological and genetic considerations, rather than on a single biochemical marker.

Copyright@ 26 Jan, 2013.

\section{REFERENCES}

1. Saggese G,Meossi C, Cesaretti G, Bottone E. Physiological assessment of growth hormone secretion in the diagnosis of children with short stature. Pediatrician 1987; 14: 121-7.

2. Smyczynska J, Lewinski A, Hilczer M, Stawerska R,
Karasek M. Partial growth hormone deficiency (GHD) in children has more similarities to idiopathic short stature than to severe GHD. Endokrynol Pol 2007; 58:182-7.

3. Awan TM,Sattar A,Khattak IG. High growth hormone levels in short stature children. J Ayub Med Coll Abbotabad 2006;18:29-33.

4. Stanley T. Diagnosis of growth hormone deficiency. Curr Opin Endocrinol Diabetes Obes 2012; 19: 47-52.

5. Webb EA, Dattani MT. Diagnosis of growth hormone deficiency. Endocr Dev 2010; 18: 55-66

6. Banerjee I, Clayton PE. Clinical utility of insulin-like growth factor-1 (IGF-1) and IGF binding protein-3 (IGFBP-3) measurements in paediatric practice. Ped Endocrinol Rev 2006; 4: 393-402.

7. Blum WF, Albertsson-Wikland K, Rosberg S, Ranke MB Serum levels of insulin-like growth factor-1 (IGF-1) and IGF-binding protein-3 reflect spontaneous growth hormone secretion. J Clin Endocrinol Metab 1993; 76: 1610-6.

8. Smyczynska J, Stawerska R, Lewinski A, Hilczer M. Do IGF-1 concentrations better reflect growth hormone (GH) action in children with short stature than the results of growth hormone stimulating tests? Evidence from the simultaneous assessment of thyroid function. Thyroid Res 2011; 4: 6 .

9. Bussieres L, Souberbielle JC, Pinto G, Adan L Noel M, Brauner $R$. The use of insulin-like growth factor 1 reference values for the diagnosis of growth hormone deficiency in prepubertal children. Clin Endocrinol (Oxf) 2000; 52: 735-9.

10. Yuksel B, Ozbek MN, Mungan NO, Darendeliler F, Budan B, Bideci A, et all. Serum IGF-1 and IGFBP-3 levels in healthy children between 0 and 6 years of age. $J$ Clin ResPed Endo 2011; 3: 84-88.

11. Awan TM, Sattar A, Khattak EG. Frequency of growth hormone deficiency in short statured children. J Coll Physicians Surg Pak 2005; 15: 295-8.

12. Lone SW, Khan YN, Atta I, Ibrahim MN, Raza J, Qamar F. Safety of insulin tolerance test for the assessment of growth hormone deficiency in children. J Pak Med 


\section{Assoc 2011;61:153-7.}

13. Ali A, Hashim R, Khan FA, Sattar A, ljaz A, Manzoor SM, Younas M. Evaluation of insulin-like growth factor-1 and insulin-like growth factor binding protein-3 in diagnosis of growth hormone deficiency in short stature children. J Ayub Med Coll Abbotabad 2009; 21: $40-45$.

14. Gilsanz V, Ratib 0. Hand Bone Age - A digital atlas $f$ skeletal maturity. Springer, 2005.

15. Smyczynska J, Lewinski A, Stawerska R, Hilczer M, Karasek M. Assessment of insulin-like growth factor1 serum concentration as a screening procedure in diagnosing children with short stature. Neuro Endocrinol Lett 2007; 28: 274-78.

16. Kayemba-Kay's S, Epstein S, Hindmarsh P, Burguet A, Ingrand $P$, Hankard $R$. Does plasma IGF-BP3 measurement contribute to the diagnosis of growth hormone deficiency in children? Am Endocrinol 2011: 72: 218-23.

\section{AUTHOR(S):}

1. DR. MUHAMMAD NADEEM HAMEED MCPS, FCPS

Department of Pediatrics

Shalamar Medical \& Dental College, Lahore, Pakistan.

2. DR. FAUZIA SADIQ

Department of Pathology

3. DR. ASIM MUMTAZ

MBBS, M. PHIL

Professor of Pathology

Shalamar Medical \& Dental College, Lahore, Pakistan.

4. Dr. Hina Mohiuddin

Department of Pathology
5. Dr. Sana Khan

Department of Pathology

6. Dr. Tariq Jaffar Quereshi

Department of Radiology

Correspondence Address:

Dr. Muhammad Nadeem Hameed

MCPS, FCPS

Department of Pediatrics

Shalamar Medical \& Dental College, Lahore, Pakistan. nadeemhameed69@yahoo.com

Article received on: 10/12/2012 Accepted for Publication: 26/01/2013 Received after proof reading: 15/03/2013

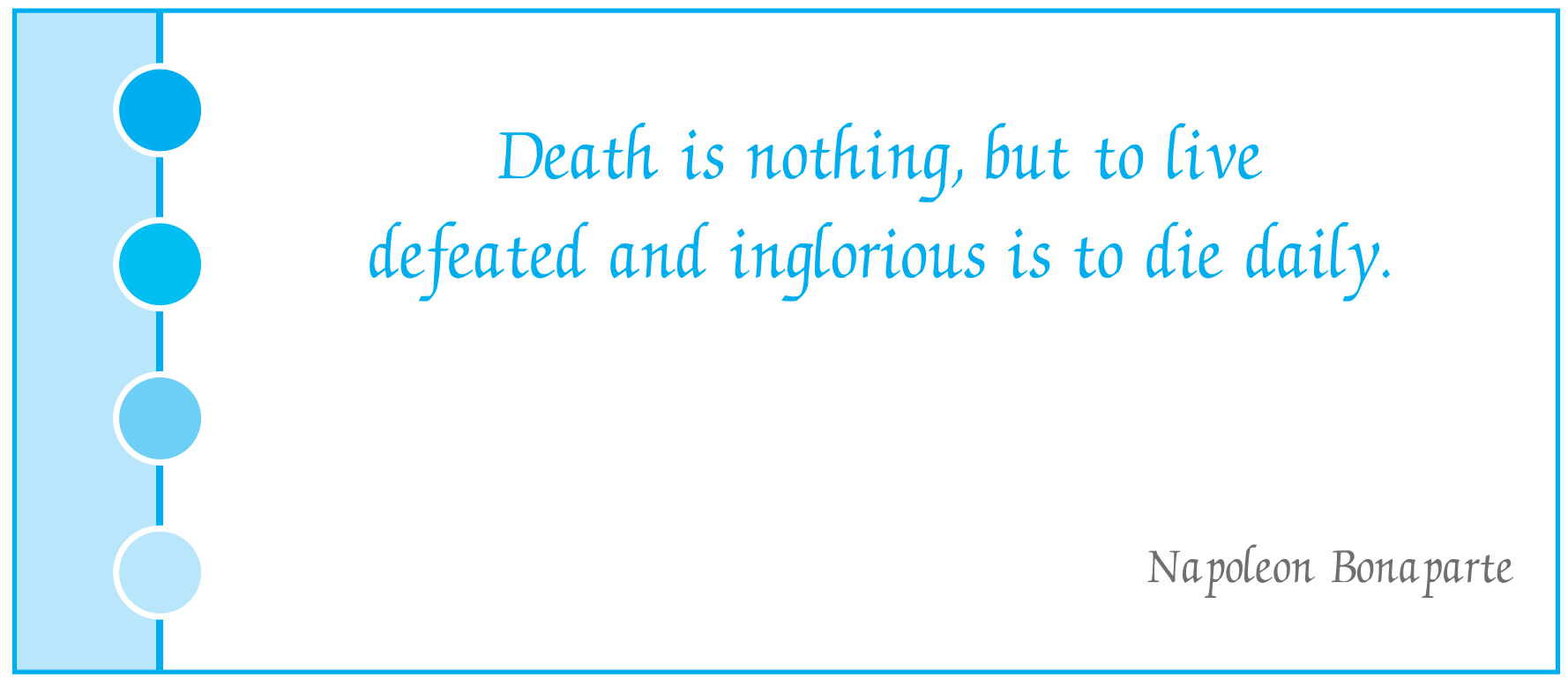

